\title{
АВТОМАТИЗАЦИЯ ПРОЦЕССА ОЧИСТКИ ВАГОНОВ ОТ ПРИМЕРШЕЙ И СЛЕЖАВШЕЙСЯ МАССЫ МАГНИТОИМПУЛЬСНЫМ СПОСОБОМ
}

\section{AUTOMATION OF THE PROCESS OF CLEANING CARS FROM EXAMPLE AND TRAINED MASS BY MAGNETIC PULSE METHOD}

O. Topchieva

Summary. The article presents a method of experimental research and mathematical modeling of the process of cleaning cars from frozen and caked mass. As a result of experiments and modeling, the dependence of the acceleration and displacement of the carriage wall on the destruction of the material in the wall was revealed, which makes it possible to control and destroy the frozen mass without damaging the car itself.

Keywords: wagon cleaning, magnetic impulse method, automation of the cleaning process, ice destruction.
Топчиева Оксана Юрьевна

Аспирант, Иркутский государственный университет путей сообщения, Красноярск o-vahrusheva@bk.ru

Аннотация. В статье представлен метод экспериментального исследования и математическое моделирование процесса очистки вагонов от примерзшей и слежавшейся массы. В результате экспериментов и моделирования выявлена зависимость ускорения и перемещения стенки вагона от разрушения материала в стенке, которая позволяет контролировать и производить разрушение смерзшейся массы без повреждения самого вагона.

Ключевые слова: очистка вагонов, магнитоимпульсный способ, автоматизация процесса очистки, разрушение льда.
$\mathbf{P}$ азгрузка вагонов от примерзших и слежавшихся грузов является большой проблемой для таких потребителей и перевозчиков как - ТЭЦ, морские порты, комбинаты (металлургические, химические, обогатительные) и так далее.

Эта проблема имеет высокую актуальность для стран с холодным климатом, в число которых входят Россия, Китай, Казахстан, Монголия, Финляндия, Швеция, Норвегия, США, Германия, Франция и других.

Первое место по добыче угля в мире занимает Китай, за ним следуют США, Австралия и Индия. По данным Национальной ассоциации объем добывающей отрасли США составляет более 230 млрд. тонн. Объем рынка угля ЦФО РФ поставляемого по ж/д составляет порядка 360 тыс. тонн в год.

Правила перевозок смерзающихся грузов на железнодорожном транспорте утверждены приказом МПС РФ от 5 апреля 1999 г. Грузы, отнесенные к смерзающимся, указаны в приложении N1 к правилам перевозок смерзающихся грузов на железнодорожном транспорте [1].

Основные способы разгрузки смерзшегося груза, на сегодняшний день, в мире - разогрев и дробление.
Тем не менее, попытки очистить полувагон от смерзшейся массы традиционными способами не эффективны выгрузка занимает большое количество времени и приводит к повреждению вагона [2-4,9].

В настоящее время, в большинстве стран, где эта проблема актуальна, ведутся разработки новых способов очистки вагонов, и усовершенствования уже существующих. Например, в ПГУПСе разработали электрогидроимпульсный способ разгрузки смёрзшегося угля. Также к решению проблемы разгрузки смерзшихся грузов подключились отраслевые учёные. Среди предложенных технологий - обработка подвижного состава и продукции различными жидкостями препятствующие замерзанию груза, а также предварительное промораживание груза.

Также проблема замерзания и слёживания груза актуальна для различных бункеров и емкостей, предназначенных для хранения, перевалки и дозирования на железнодорожном транспорте и в других отраслях промышленности, где требуется разгрузка, погрузка сыпучих грузов и их транспортировка.

Таким образом, разработка новых эффективных и экономичных способов разгрузки замерзшего и слежавшегося груза актуальна [5-10]. 


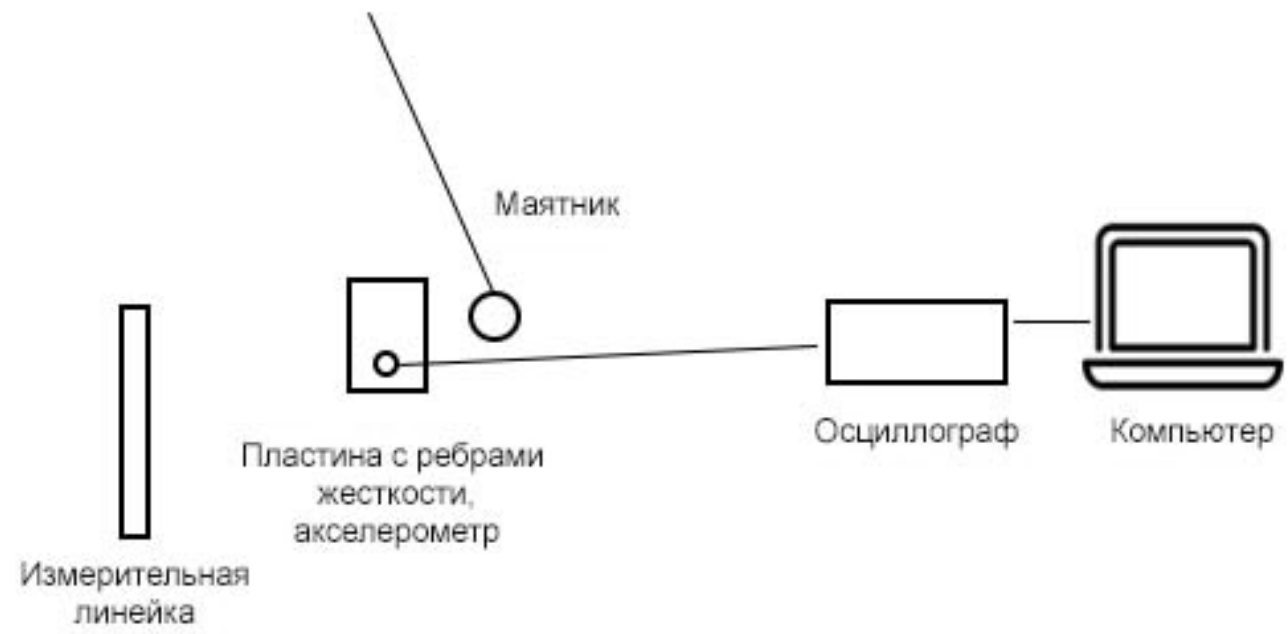

Рис. 1. Функциональная схема испытаний

В рамках научной темы при поддержке при поддержке Фонда содействия инновациям была изготовлена и апробирована на полигоне Красноярского института железнодорожного транспорта - установка очистки вагонов магнитоимпульсным способом [11-13].

Для решения поставленных задач по автоматизации имеющейся установки сформулированы такие критерии контроля разрушения как максимальные и минимальные значения ускорения и перемещения. Для подтверждения сформулированных критериев разрушения проведены следующие эксперименты и численное моделирование.

Экспериментальное исследование очистки пластины от примерзшего льда и гравия:

Функциональная схема испытаний представлена на рисунке 1. Для эксперимента к пластине примораживались последовательно лёд и гравий с толщинами 40мм, 60мм, 80мм (рис. 2-3).

На пластине был зафиксирован датчик ускорения, подключенный к осциллографу (рис. 3).

В качестве источника удара был применён маятник. При помощи металлического шара удары наносились по центру пластины. Металлический шар, закрепленный на упругой веревке, отводился на заданное фиксированное расстояние.

Удары наносились по центру пластины и проводились до полного разрушения льда и гравия. При каждом ударе снимались показания датчика ускорения. На рисунках 4 и 5 представлены показания осциллографа от акселерометра при нанесении ударов, когда лед плотно прилегает к пластине.
По результатам эксперимента была выявлена следующая зависимость.

Когда материал плотно прилегает к пластине ускорение пластины самое низкое, наибольшее значение ускорения возникает в момент удара шарика о пластину.

При появлении трещин на материале и его отставания от пластины ускорение возрастает.

На свободной пластине, без материала ускорение наибольшее. Такая зависимость ускорений характерна для обоих материалов.

По результатам натурного эксперимента были проведены расчеты, для получения исходных данных, необходимых для моделирования. А именно из расчетов были получены, сила импульса, развиваемая маятником при ударе о лёд 1,232 Нс, и при ударе о гравий $1,8 \mathrm{Hc}$.

Расчет максимальной скорости шарика маятника.

$$
\begin{aligned}
& m g h=\frac{m v^{2}}{2} ; \\
& v=\sqrt{2 g h} ;
\end{aligned}
$$

Расчет импульса маятника.

$$
S=m v
$$

Имея все необходимые данные, было проведено моделирование удара о пластину в системе автоматизированного проектирования Creo с ребрами жесткости в свободном состояние и с материалами льдом и гравием. 


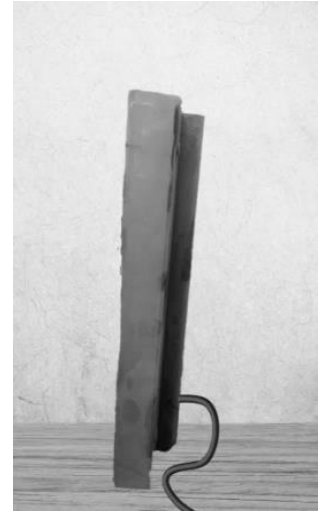

Рис. 2. Примерзший материал

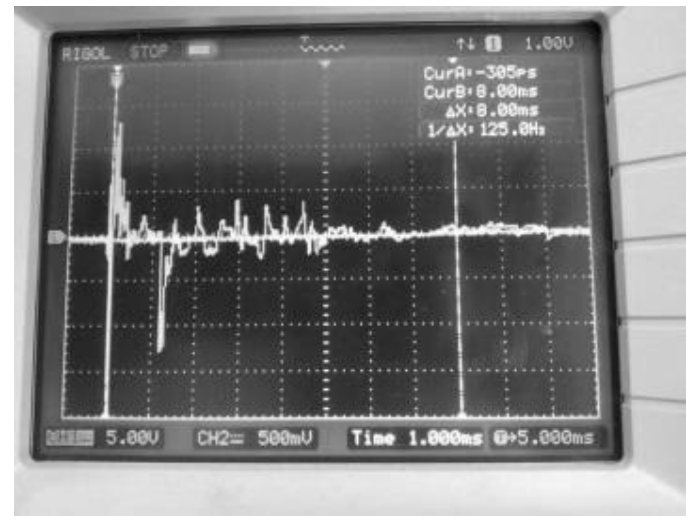

Рис.4.

Напряжение - лед толщиной 40мм (14B)

В рамках данного научного исследования были исследованы прочностные характеристики смерзшихся грузов, которые в значительной мере влияют на эффективность очистки вагона и описаны подходы к дальнейшей автоматизации готовой конструкции установки.

Для расчета пределов прочности материалов были проведены испытания образцов на определение предела прочности при сжатии.

В рабочую зону стенда между штоком цилиндра и опорной плитой помещается испытуемый образец. При помощи дросселя и кнопки управления регулируется скорость нарастания усилия на испытуемый образец. Контроль скорости набора давления и давления разрушения образца происходит при помощи цифрового манометра. В рабочем состоянии установка остается до разрушения испытуемого образца. После разрушения образца стенд возвращается в исходное положение. Для экспериментов и моделирования были использованы образцы прямоугольной формы.

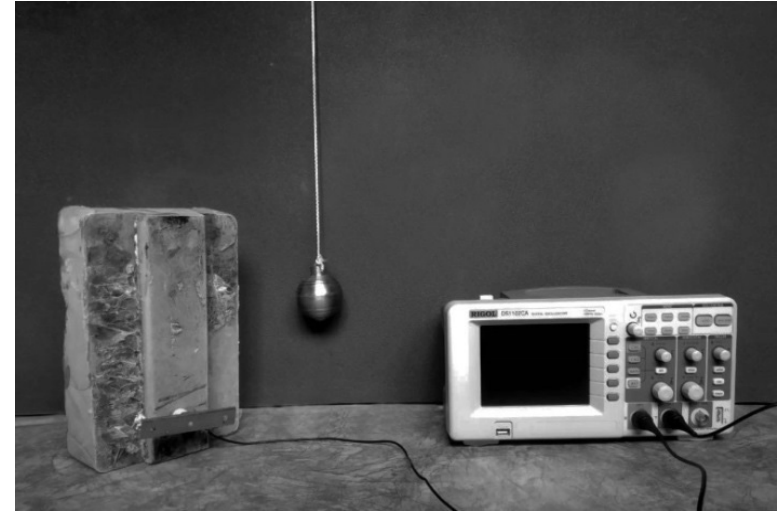

Рис.3. Лабораторный стенд

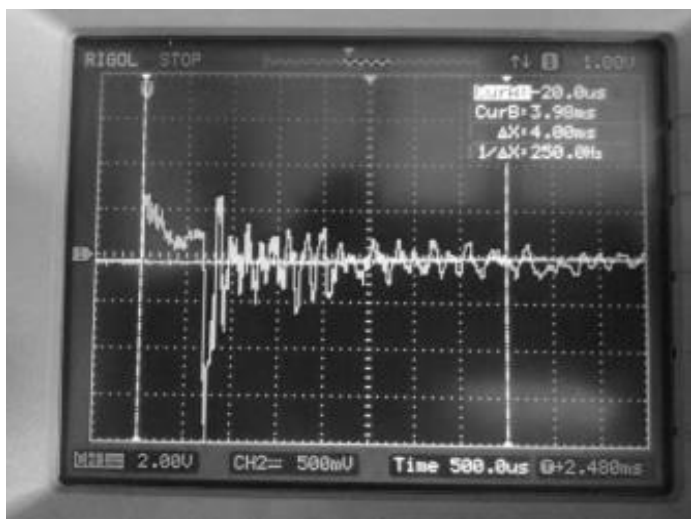

Рис.5.

Напряжение - лед толщиной 60мм (9B)

В результате эксперимента рассчитаны пределы прочности для льда и замерзшего гравия (далее гравий). Предел прочности льда равен 1,73МПа, а предел прочности гравия 6, 04МПа. Также по закону Гука был рассчитан модуль Юнга для гравия, он равен 6,5 ГПа. Коэффициент Пуассона был принят 0,3.

Так как рассчитанный предел прочности для льда соответствует известной прочности льда, то можно сказать, что рассчитанный предел прочности для гравия также верен. Результаты компьютерного моделирования льда в том же самом состоянии соответствуют эксперименту (рисунок 9), при заданном усилии 844кг лед достигает установленного предела прочности и разрушается.

Таким образом, можно сказать, что эксперимент и компьютерное моделирование проведены верно, и соответствуют друг другу, как для льда, так и для других материалов, исследованных при тех же условиях. В результате также установлено, что при достижении воздействия усилия 2870кг на гравий (рисунок 10) - образец разрушился. 


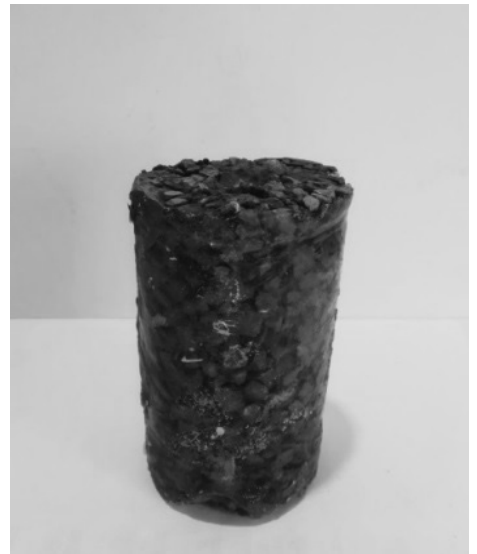

Рис. 6. Модель льда с примесью гравия

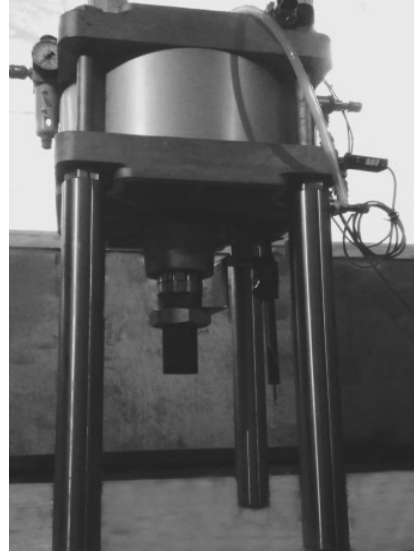

Рис.7. Экспериментальный стенд

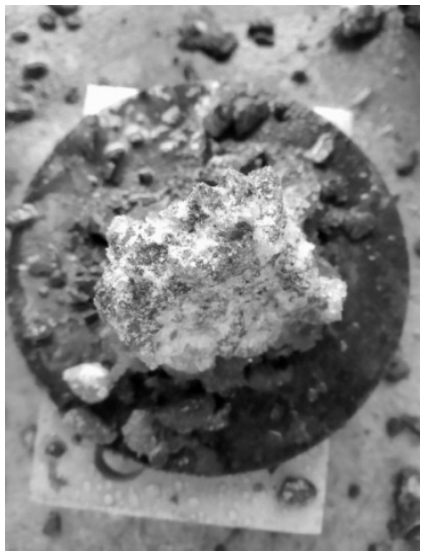

Рис.8. Лед с примесью гравия после разрушения
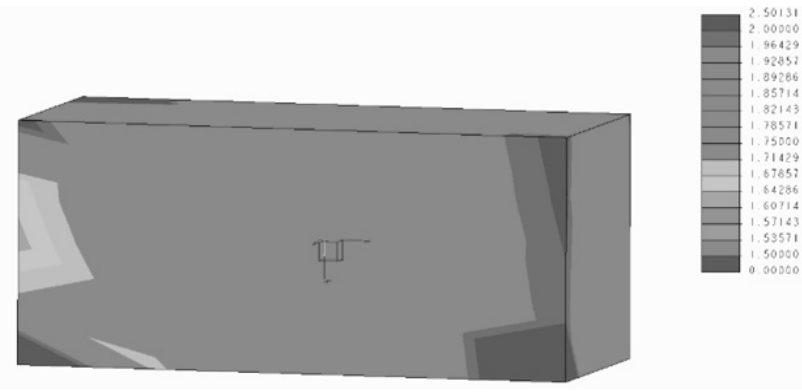

Рис. 9. Моделирование удара по льду площадью

$\mathrm{S}=47$ см2 и силой $\mathrm{F}=844 к г$ (Fig. 9. Simulation of impact on ice area $\mathrm{S}=47 \mathrm{~cm} 2$ and force $\mathrm{F}=844 \mathrm{~kg}$ )

\section{Математическое моделирование очИстКИ п^астИны от примерзшего ^ьла и гравия}

Имея все необходимые данные были проведены моделирования ударов о пластину с ребрами жесткости в свободном состоянии и с материалами льдом и гравием, где все размеры и усилия соответствовали эксперименту.

Полученные результаты оказались близкими к эксперименту. Например для льда толщиной 40 мм ускорение $2800 \mathrm{~m} / \mathrm{c}^{2}$ (рис. 11), что соответствует 14В в эксперименте, для льда толщиной 60 мм 2000 м/ ${ }^{2}$, что близко к показаниям эксперимента 9,5В. Ускорение свободной пластины 8000 м/ $\mathrm{c}^{2}$. Таким образом было доказано что физикомеханические свойства моделей материалов соответствует испытываемым образцам. На основании этих данных были проведены различные

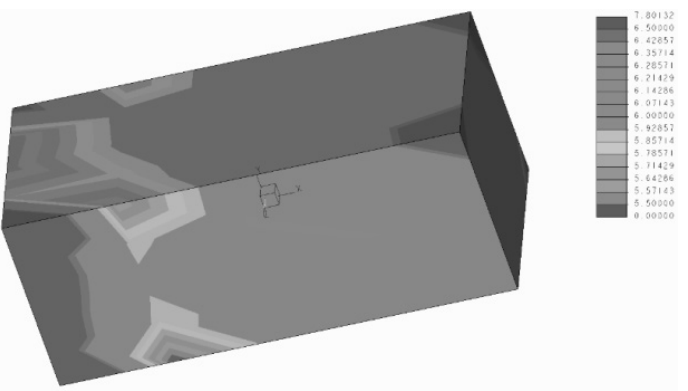

Рис. 10. Моделирование удара по льду с примесью гравия площадью $\mathrm{S}=47$ см2 и силой $\mathrm{F}=2870$ кг (Simulation of impact on ice with admixture of gravel area $S=47 \mathrm{~cm} 2$ and force $F=2870 \mathrm{~kg}$ )

моделирования, по результатам которых были получены графики.

Был проведён анализ изменения ускорения и перемещения пластины при ударе, по мере уменьшении высоты материала с постоянной силой импульса. В условиях данной работы это будет соответствовать уровню материала в вагоне, который при разгрузки изменяется.

Из приведённых графиков видно, что зависимость имеет не линейный характер. При уменьшении уровня материала более чем наполовину ускорение и перемещение резко возрастают, и могут привести к повреждению стенки вагона. Что бы этого не допустить по мере разгрузки материала сила импульса должна уменьшатся.

Для выявления зависимости ускорения от силы удара была проведена серия моделирований, где по модели пластины со льдом не изменой геометрии, произво- 


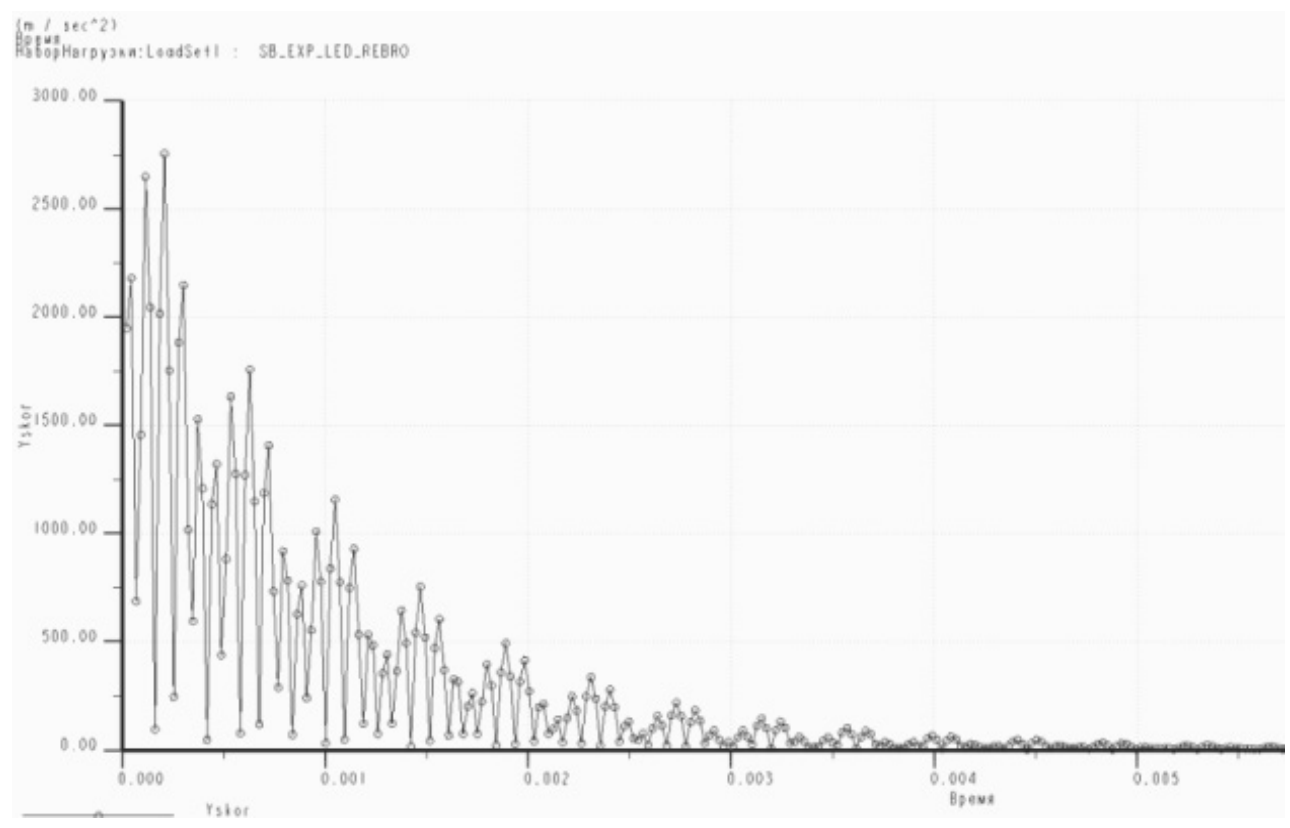

Рис. 11. Ускорение лед 40мм (2800 м/ $\left.\mathrm{c}^{2}\right)$

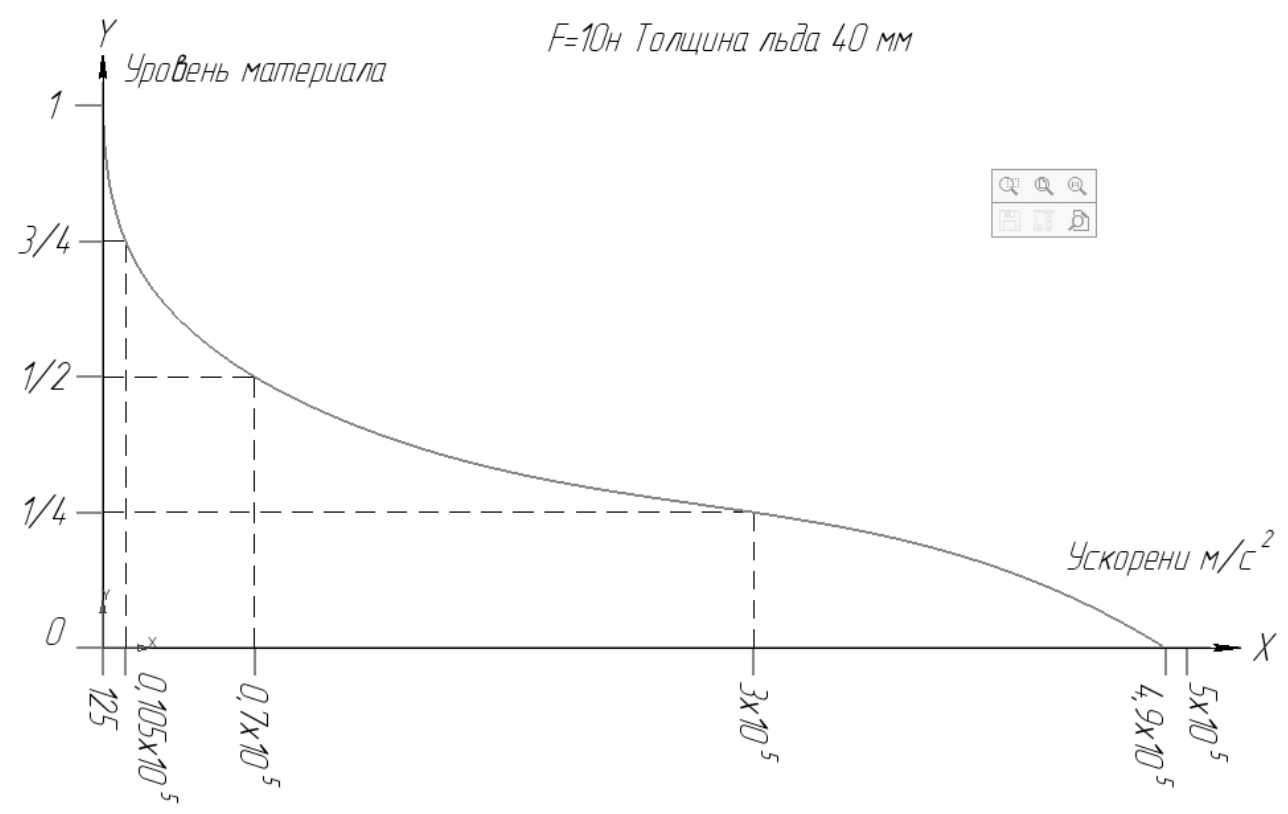

Рис. 12. Ускорение листа в зависимости от уровня материала

дились удары с различной силой и снимались показания ускорения пластины.

Из графика видно, что изменение ускорения от силы импульса имеет близкую к линейной зависимость, которую можно выразить уравнением $\mathrm{F}=\mathrm{k}^{*} \mathrm{a}$

Где F-сила удара по пластине (н), а-ускорение стенки пластины, k-поправочный коэффициент. Для данной мо- дели принимаем что ускорение не должно превышать значений, полученных в диапазоне от 1 до 1/2. Выразим этот участок графика уравнением $\mathrm{n}=1 /$ а для а диапазоне от 0 до $\mathrm{m}$. Где $\mathrm{n}$ это уровень материала. Из этих двух уравнениях получаем уравнения усилия импульса в зависимости от уровня материала. $\mathrm{F}=\mathrm{k}^{*} 1 / \mathrm{n}$.

Таким образом зная уровень материала в вагоне, можно в автоматическом режиме рассчитываться силу 


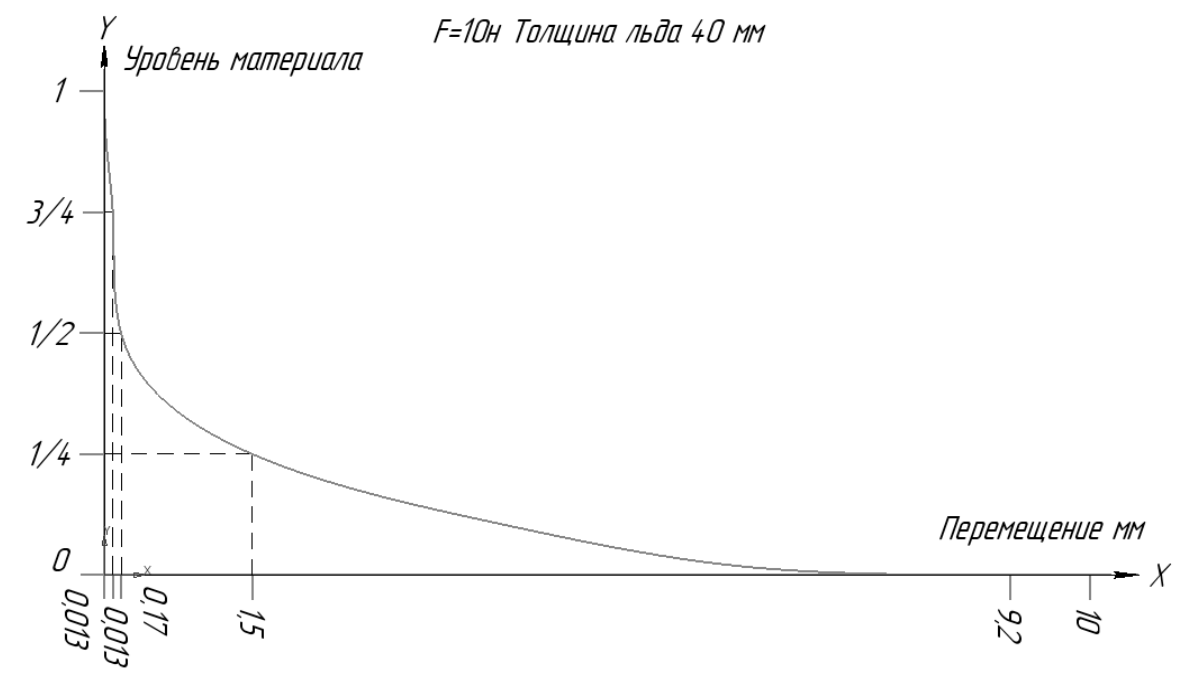

Рис. 13. Перемещение листа в зависимости от уровня материала

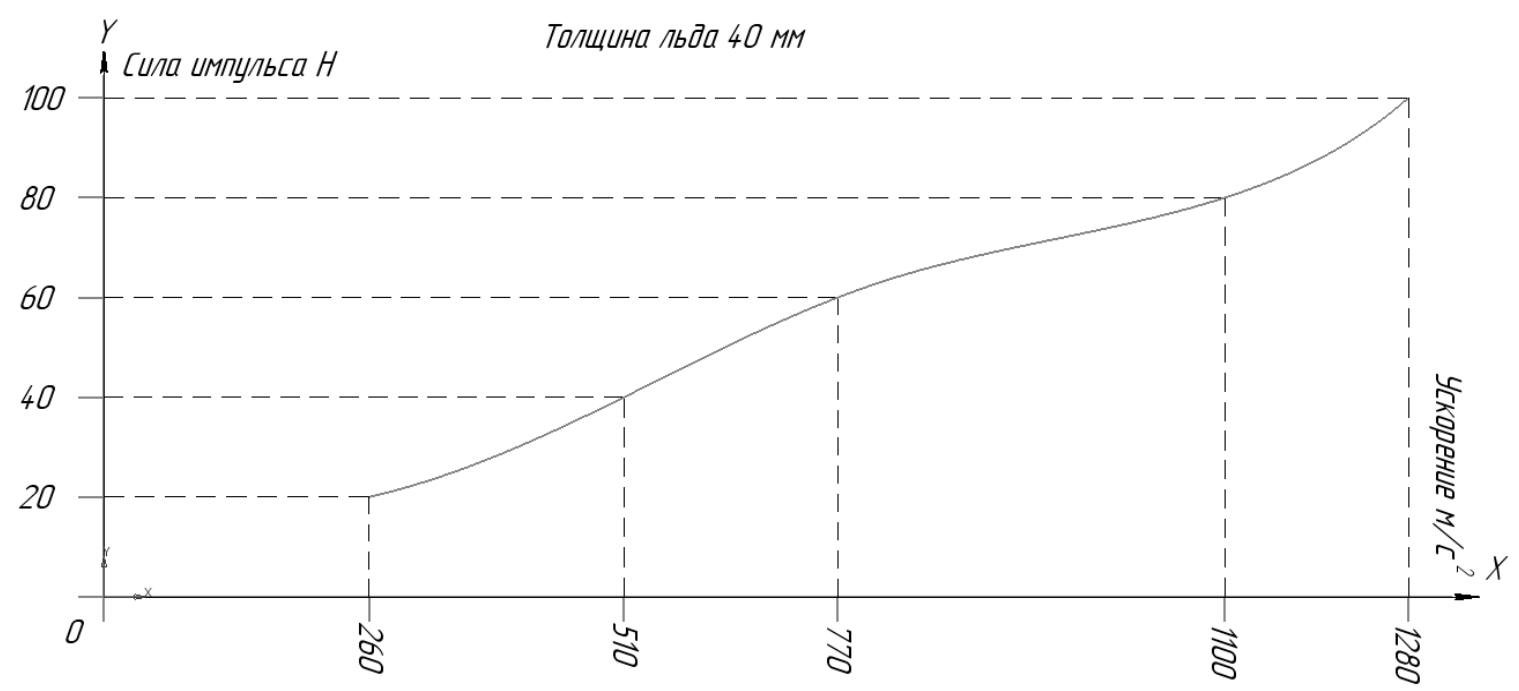

Рис. 14. Ускорение листа в зависимости от силы импульса

удара, которая не приведёт к повреждению стенки вагона.

И повторять такие циклы до полной очистки вагона.

Таким образом в работе проведены теоретические и экспериментальные исследования, которые позволяют обосновать технические решения в области автома- тизации процесса очистки вагона от примёрзшей и слежавшейся магнитоимпульсным способом, внедрение которых позволит устранить недостатки существующих способов, в том числе сформулированы критерии разрушения намерзшего материала, проведены эксперименты по разрушению материалов и численное моделирование для подтверждения выдвинутых критериев, а также предложены решения по дальнейшей автоматизации имеющейся установки.

\section{ЛИТЕРАТУРА}

1. Приказ МПС РФ от 5 апреля 1999 г. N20Ц «0б утверждении Правил перевозок смерзающихся грузов на железнодорожном транспорте».

2. M. Endres. Experimental study of two electro-mechanical de-icing systems applied on a wing section tested in an icing wind tunnel/ M. Endres, H. Sommerwerk, C. Mendig, M. Sinapius, P. Horst// Ceas Aeronautical Journal — 2017 — C. 429-439. 
3. Ратушняк В.С. Обоснование необходимости разработки нового способа очистки проводов ЛЭП от гололедных отложений // Инновационные технологии на железнодорожном транспорте: труды XXI Межвузовской научно-практической конференции КрИЖТ ИрГУПС (г. Красноярск, 07.11.2017 г.) / редкол.: В.С. Ратушняк (отв. ред.) [и др.]; КрИЖТ ИрГУПС.—Красноярск: КрИЖТ ИрГУПС, 2017.—290 с.— С. 62-69.

4. Левенсон С.Я. Повышение эффективности выпуска смерзшегося угля из полувагонов // Горный информационно-аналитический бюллетень (научно-технический журнал). - 2010 - № . 2

5. Е.С. Ильин. 06 эксперименте применения магнитоимпульсного способа по очистке вагона от примерзшей массы/Е.С. Ильин, 0.Ю. Вахрушева, В.С. Ратушняк// Современные технологии. Системный анализ моделирование — ИрГУПС — № 1, 2018 г._ С. 117-122.

6. Е.С. Ильин. Experience in the magnetic pulse installation model use to clean the gondola car from the frosted and packed cargo/ Е.С. Ильин, $0 . Ю$. Вахрушева, В.С. Ратушняк, А.В. Юрьев// Материалы The Sixth International Symposium on Innovation and Sustainability of Modern Railway, ISMR2018, ИрГУПС-2018г-C.237-245

7. Е.С. Ильин. Автоматизация процесса очистки вагона от примерзшей и слежавшейся массы магнитоимпульсным способом/ Е.С. Ильин, 0.10 . Вахрушева// Труды Всероссийской научно-практической конференции: 115 лет Железнодорожному образованию в Забайкальском Крае - ЗабИЖТ — 2017 г.C. 146-152.

8. Магнитоимпульсный способ очистки вагона. Результаты компьютерного моделирования / 0.Ю. Вахрушева, Е.С. Ильин, В.С. Ратушняк, А.В. Лившиц // Молодая наука Сибири. - 2018. — № 1 (1).- С. 75-79.

9. Некоторые аспекты выбора средств борьбы с гололедными отложениями на ЛЭП / В.С. Ратушняк, В.С. Ратушняк, Е.С. Ильин, 0.Ю. Вахрушева // Известия Транссиба. - 2019. — № 1 (37). - С. 102-111

10. Об эксперименте применения магнитоимпульсного способа по очистке вагона от примерзшей массы / Е.С. Ильин, 0.Ю. Вахрушева, В.С. Ратушняк // Современные технологии. Системный анализ. Моделирование.— 2018. — № 1 (57). — C. 117-123.

11. Патент 2681621. Российская Федерация. Устройство очистки полувагона / Е.С. Ильин, А.В. Юрьев, В.С. Ратушняк. — Патент на изобретение RU2681621 C1, 11.03.2019. Заявка № 2017136368 от 16.10.2017.

12. Патент 2660260. Российская Федерация. Электрогидроимпульсный способ разрушения железобетонных изделий с применением пинч-эффекта / Ратушняк В.С., Юрьев А.В., Ильин Е.С., Трухина И.С. — Патент на изобретение RU2660260 C1, 05.07.2018. Заявка № 2017132206 0т 15.09.2017.

13. Патент 2666225. Российская Федерация. Генератор импульсных токов для высоковольтных электрогидравлических технологий / В.С. Ратушняк, А.Е. Гаранин, А.В. Юрьев, Е.С. Ильин — Патент на изобретение RU2666225 C1, 06.09.2018. Заявка № 2017123323 от 03.07.2017.

(c) Топчиева Оксана Юрьевна ( o-vahrusheva@bk.ru)

Журнал «Современная наука: актуальные проблемы теории и практики»

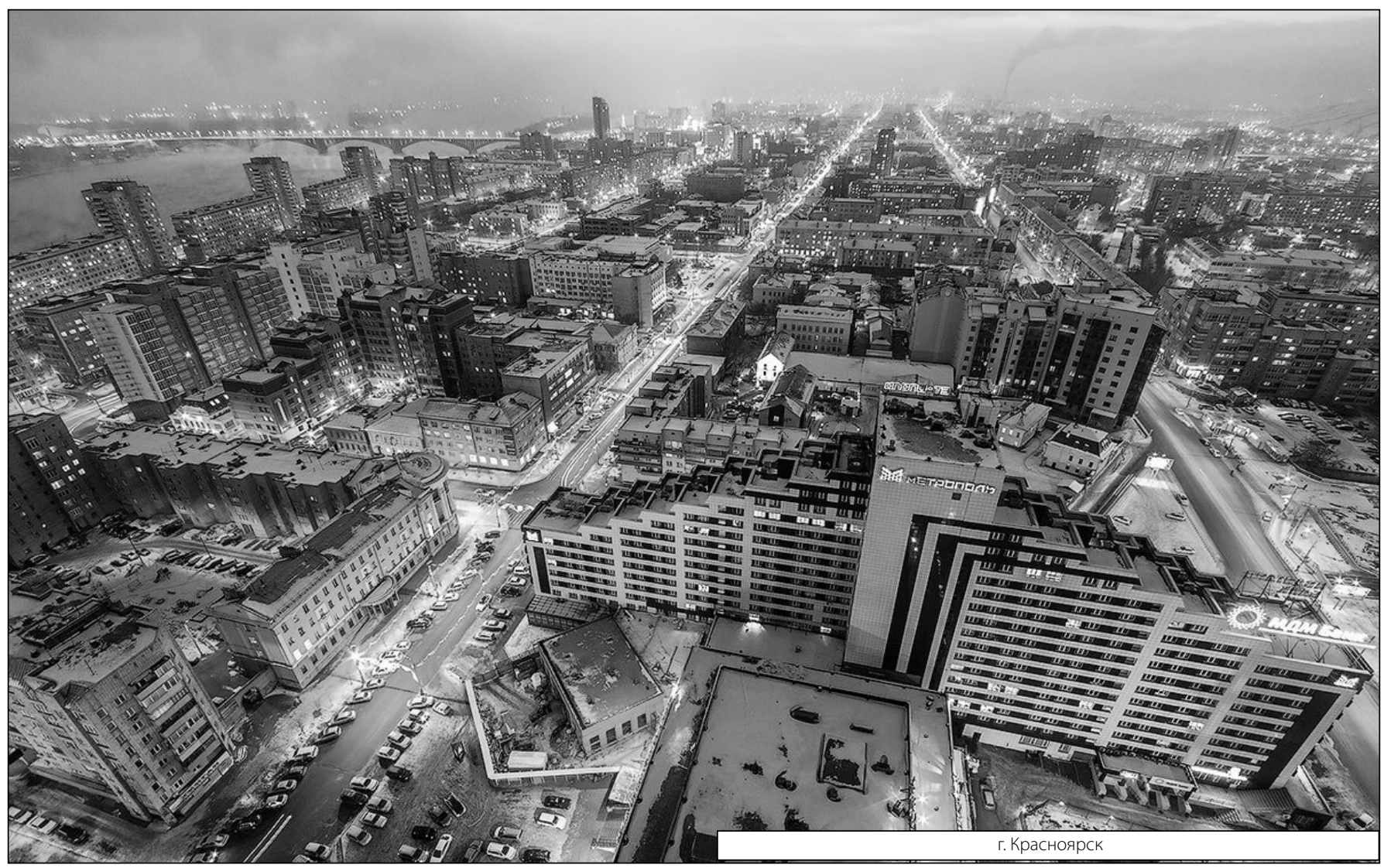

